\title{
Coğrafi Bilgi Sistemlerinin Geoteknik Alanında Değişken Zemin Ortamında Uygulaması
}

\author{
${ }^{1}$ Ertan Bol, ${ }^{1}$ Sedat Sert ve ${ }^{* 1}$ Aşkın Özocak \\ ${ }^{* 1}$ Faculty of Engineering, Department of Civil Engineering, Geotechnical Lab., Sakarya University, Turkey
}

\section{Özet}

Yatay ve düşey yönde ani zemin değişimlerinin gözlenebileceği alüviyal kökenli çökel ortamlarda özellikle çalışma alanı büyüdükçe Geoteknik açıdan karar verme süreci karmaşı bir hal alabilmektedir. Bu çalışmada orta ölçekli bir araştırma alanında Geoteknik değerlendirmenin Coğrafi Bilgi Sistemleri (CBS/GIS) eş̧liğinde yürütülmesi açıklanmıştır. Araştırma arazi koni penetrasyon deneyi (CPT) verileri ile gerçekleştirilmiştir. Adapazarı ovasının tipik zeminlerini bulunduran orta ölçekli bir sanayi sitesinin dış sınırları ve içerdiği bloklar CBS yazılımı olan "MapInfo" programı ile sayısallaştırılmıştır. CPT'den elde edilen tüm veriler ile bu verilerden türetilen ilgili Geoteknik özellikler veri tabanına aktarılmıştır MapInfo yazılımı ile veri tabanı arasında gerekli ilişkiler kurularak taşıma gücü ve sıvılaşma bölgelerini gösterir tematik haritalar hazırlanmıştır. Çalışma sonunda CBS'nin bu gibi ortamlarda Geoteknik bakımdan karar verme süreçlerini hızlandırdığı ve yapılan değerlendirmelerin de daha doğruyu yansıttı̆̆ kanaatine varılmıştır. Bununla birlikte inceleme noktalarının araziye düzgün dağılımını sağlayan uygun bir arazi çalışması gerçekleştirildiğinde CBS'nin çalışmalara hız katacağı ve maliyetleri düşüreceği de açıktır.

Anahtar kelimeler: Coğrafi Bilgi Sistemleri (CBS), Geoteknik Değerlendirme, Sıvılaşma, Adapazarı

\begin{abstract}
Geotechnical decision process can be complicated especially in larger alluvial areas where sudden lateral and vertical soil changes observed. In this study, geotechnical evaluation by using Geographical Information Systems (GIS) of a medium-scale research area was explained. The research was carried out with in-situ cone penetration test (CPT) data. The external boundaries of this medium-sized industrial site, which includes the typical soils of the Adapazarı plain, were digitized by the GIS software "MapInfo". All the data obtained from CPT and the related geotechnical properties were transferred to the database. The necessary relations between MapInfo and the database were established and thematic maps, that show the bearing capacity and liquefaction regions, were prepared. It was concluded that the use of GIS accelerates the decision-making processes in geotechnical environments and the evaluations are more accurate. Moreover, it is also clear that if an appropriate research program, which ensures the research points are properly distributed in the area, is carried out, CBS will accelerate the conclusion and will reduce the costs.
\end{abstract}

Key words: Geographic Information System (GIS), Geotechnical Evaluation, Liquefaction, Adapazari

\section{Giriş}

Arazilerin geoteknik açıdan yapılaşmaya yönelik değerlendirmesi klasik olarak; arazi ve laboratuvar verilerinin toplanması, zemin yapısının karakterize edilmesi, her bir katmana amaca uygun parametrelerin atanması, analizlerin yapılması ve bunların sonuçlarının bir rapor halinde

*Corresponding author: Address: Faculty of Engineering, Department of Civil Engineering Sakarya University, 54187, Sakarya TURKEY. E-mail address: ozocak@sakarya.edu.tr, Phone: +902642955738 
sunulması aşamaları ile yürütülür. Yatayda ve düşeyde ani değişimler gösteren zemin kesitlerinde, çalışılan arazinin ve üzerinde yapılacak yapının alanlarının artması ile bu süreç karmaşık bir hal almaktadır. Özellikle orta ve büyük ölçekli alanlarda gerçekleştirilen klasik zemin incelemelerinde araştırma noktalarının aralığı, maliyetleri ve sarf edilecek zamanı aşağı çekmek için mümkün olduğunca geniş tutulmaktadır. Bu durum da özellikle yanal zemin değişimi gösteren alüviyal alanlarda değişimin sınırlarını belirlemede zorluklara yol açmaktadır. Günümüzde, konumsal bilgiyi sayısal bir yapıya dönüştürebilen Coğrafi Bilgi Sistemlerinin (CBS) (geographic information system, GIS) kullanımı ile bu tür problemlerin kolaylıkla üstesinden gelinebileceğini söylemek yanlış olmayacaktır. Coğrafi Bilgi Sistemleri, yeryüzüne ait her türlü verinin gerçek koordinatları ile birlikte bir veri tabanında toplanmasını, arzu edilen veri topluluğu üzerinde çeşitli analizlerin yapılmasını ve sonuçların harita, çizelge veya grafikler şeklinde gösterilmesini sağlamak üzere geliştirilmiş olan bir bilgisayar sistemidir [1].

Literatüre bakıldığında çok farklı disiplinlerde uygulama alanı bulabilen CBS'in Geoteknik alanında yeterince yer bulamadığı anlaşılmaktadır. Bu çalışmada, orta ölçekli bir arazide yapılaşmaya yönelik olarak yapılması gereken Geoteknik değerlendirmenin Coğrafi Bilgi Sistemleri $(C B S)$ yardımı ile yürütülmesi anlatılmıştır. İnceleme alanı Adapazarı kentinin hemen güneyinde bulunan sanayi bölgesindedir. Çalışma alanını oluşturan zeminler Sakarya Nehri'nin ovaya yaymış olduğu alüviyal birikimlerden oluşmaktadır. Yeraltı suyunun da yüksek olduğu bu tip zeminlerde özellikle deprem sırasında zemin problemlerinin yaşanması ihtimali her zaman göz önünde bulundurulmalıdır. Zira 1999 depreminde Adapazarı kent merkezinde üst yap1 hasarlarının bir kısmının kum ve siltlerin sıvılaşmasından ve yumuşak killerin kayma direncini yitirmesinden kaynaklandığı bilinmektedir $[2,3,4,5,6]$.

\section{Materyal ve Metot}

Coğrafi Bilgi Sistemi (geographic information system, GIS), yeryüzü referanslı grafik veya grafik olmayan verilerin kullanıcının ihtiyacını karşılayacak biçimde toplanması, depolanması, işlenmesi, analiz edilmesi, yönetilmesi ve sunulması işlemlerini yerine getiren donanım ve yazılım bileşenlerinden oluşan bir bilgi sistemidir. Bir CBS'nin kurulabilmesi için gerekli temel elemanlar; coğrafi veriler, CBS donanımı, CBS yazılımı, personel ve amaca uygun bir yöntemdir (Şekil 1).

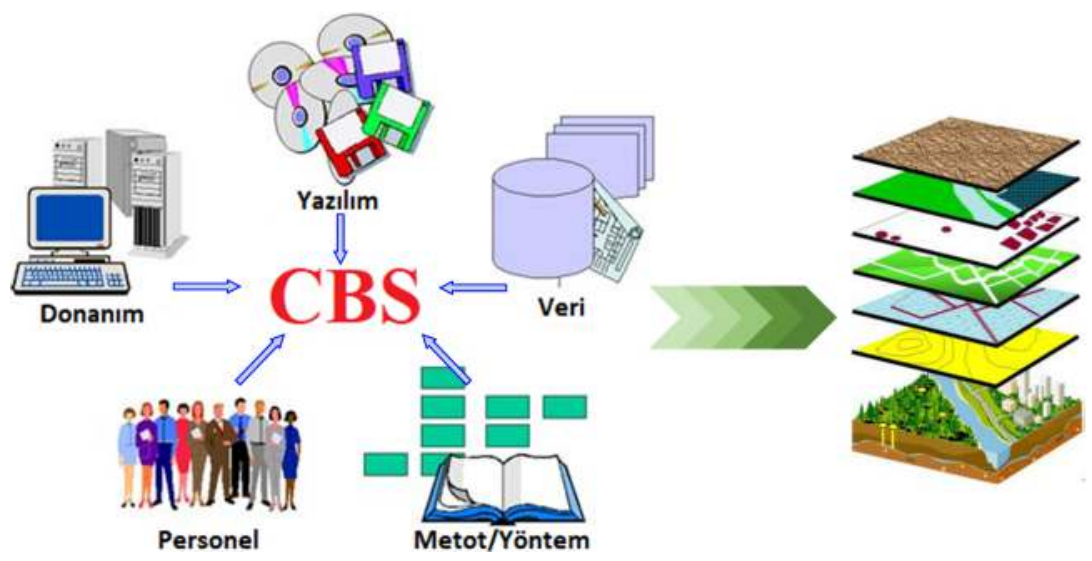

Şekil 1. Coğrafi Bilgi Sistemi (CBS) bileşenleri 
CBS'nin geoteknik alanında kullanılmasında esas olan; arazi ve laboratuvar verilerinin toplanması ve uygun formatta bir veri tabanının oluşturulmasıdır. Bu aşamayı izleyerek verilerin analiz sonuçlarının sunulabileceği haritaların sayısal ortamda oluşturulması gerekmektedir. Bu haritalar çalışılan alanın büyüklüğüne göre detaylandırılabilirler (ada, mahalle, ilçe veya şehir ölçeği). Karmaşayı önleme açısından bu çalışmada, orta ölçekli bir sanayi sitesinin bloklarını çevreleyen dış sınırlarının $\left(148.135 \mathrm{~m}^{2}\right.$ ) sayısallaştırılması tercih edilmiştir (Şekil 2). Bir coğrafi bilgi sisteminde eldeki verilerden yola çıkılarak, çalışılan bölgede pek çok tabaka oluşturulur ve böylece amaca ulaşılır. Dolayısıyla veri tabanı ve temel haritalar ortaya çıktıktan sonra, verilerin harita üzerinde işlenerek gerekli tematik harita tabakalarının ortaya çıkartılması ihtiyacı, bir yandan veri tabanı yazılımında gerekli sorgulamalar yapılarak, bir yandan da amaca uygun seçilen bir CBS programında analizler yapılarak karşılanır.

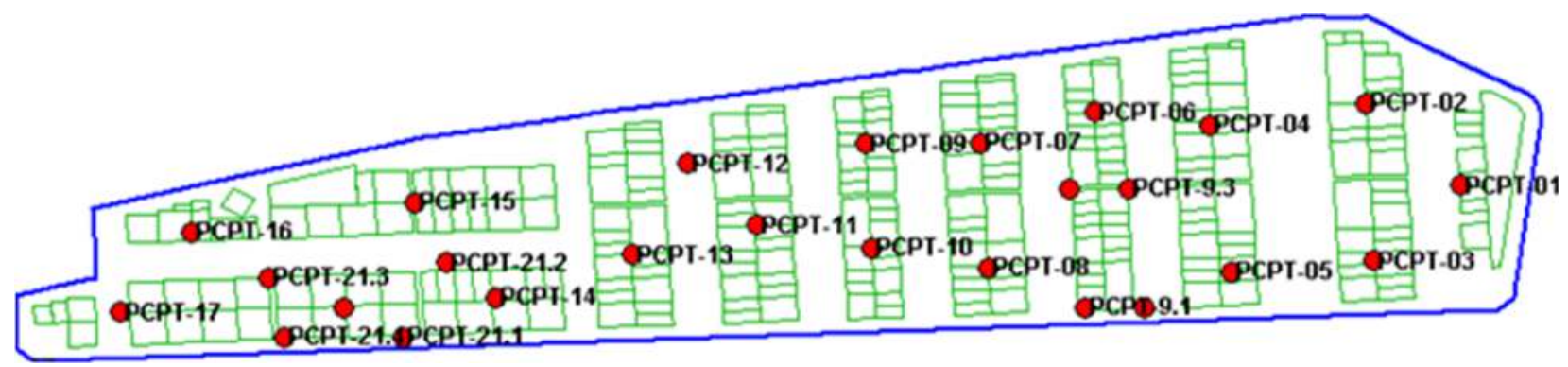

Şekil 2. İnceleme alanı ve sondalama noktaları

\subsection{Veri tabanı}

Bu çalışma kapsamında incelenen alanda inşa edilmesi düşünülen şerit temelli sanayi yapılarının zemin özelliklerini ortaya koymak açısından özel bir firma tarafından sondajlı araştırma yapılmış ve söz konusu bu çalışmada tüm alanın sıvılaşma potansiyeline sahip olduğu öngörüsünde bulunulmuştur. Özellikle yeraltı su seviyesinin yüksek olduğu bu gibi alüviyal arazilerde sıvılaşma tanısı konulan zeminlerin üzerine yap1 yapılmadan önce iyileştirilmesi gerekmektedir. $\mathrm{Bu}$ durumda tüm yapıların altına uygulanacak herhangi bir iyileştirme yönteminin muazzam bir maliyet ve zaman kaybı getireceği aşikârdır. Bu sorunun üstesinden gelebilmek için söz konusu alanda ikinci bir çalışma sadece Koni Penetrasyon Deneyi (CPT) verileri ışığında yapılmıştır. İnceleme alanında Sakarya Üniversitesi'nin sahip olduğu boşluk suyu basınçlarının da okunduğu arazi koni penetrasyon deney aleti (PCPT) ile 26 noktada toplam derinliği $400.68 \mathrm{~m}$ olan sondalama deneyi gerçekleştirilmiştir. Arazide gerçekleştirilen sondalama noktaları Şekil 2'de, koordinat, derinlik ve yeraltı suyu (YASS) bilgileri ise Tablo 1'de verilmektedir.

\subsection{Zemin özellikleri}

Çalışma alanında gerçekleştirilen sondalama çalışmalarına göre alan zeminlerinin kil-silt-kum tabakalarının farklı kombinasyon ve kalınlıklarda ardalanmasıyla meydana geldiği anlaşılmaktadır. Arazide üst kesimlerde genellikle az siltli killi birimler bulunmakta ve bu kil tabakasının kalınlığı yer yer 5.00 metreyi bulmaktadır. Daha sonra değişken kalınlıklara sahip ve sıvılaşma riski açısından potansiyel teşkil eden siltli kum ve kumlu siltleri içeren zeminlerle karşılaşılmaktadır. Ortalama 11.00-12.00 m derinliklerden sonra ise killerin hâkimiyeti tekrar belirginleşmektedir. Ayrıca çalışma alanının doğu kesimlerinde zemin yüzeyine kalınlığı $60 \mathrm{~cm}$ 
ile $1.50 \mathrm{~m}$ arasında değişen kontrolsüz dolgu serildiği tespit edilmiştir. Yapılan ölçümlerde yer altı su seviyesinin güncel kotlara göre yüzeyden 1.50 ile $3.50 \mathrm{~m}$ arasında aşağıda bulunduğu anlaşılmıştır (Tablo 1). Bu farklılığın arazide bulunan kot farklılıklarından ve su taşır tabakaların dağılımından kaynaklandığı düşünülmektedir.

Tablo 1. Sondalama noktaları koordinatları

\begin{tabular}{ccccc|ccccc}
\hline $\begin{array}{c}\text { PCPT } \\
\text { No }\end{array}$ & $\begin{array}{c}\text { Enlem } \\
(\mathbf{N})\end{array}$ & $\begin{array}{c}\text { Boylam } \\
(\mathbf{E})\end{array}$ & $\begin{array}{c}\text { Derinlik } \\
(\mathbf{m})\end{array}$ & $\begin{array}{c}\text { YASS } \\
(\mathbf{m})\end{array}$ & $\begin{array}{c}\text { PCPT } \\
\mathbf{N o}\end{array}$ & $\begin{array}{c}\text { Enlem } \\
(\mathbf{N})\end{array}$ & $\begin{array}{c}\text { Boylam } \\
(\mathbf{E})\end{array}$ & $\begin{array}{c}\text { Derinlik } \\
(\mathbf{m})\end{array}$ & $\begin{array}{c}\text { YASS } \\
(\mathbf{m})\end{array}$ \\
\hline PCPT-01 & $40.734518^{\circ}$ & $30.412334^{\circ}$ & 13.64 & 3.10 & PCPT-14 & $40.733768^{\circ}$ & $30.405836^{\circ}$ & 16.66 & 2.20 \\
PCPT-02 & $40.735069^{\circ}$ & $30.411693^{\circ}$ & 17.68 & 2.30 & PCPT-15 & $40.734407^{\circ}$ & $30.405289^{\circ}$ & 18.66 & 2.40 \\
PCPT-03 & $40.734012^{\circ}$ & $30.411747^{\circ}$ & 09.42 & 2.00 & PCPT-16 & $40.734208^{\circ}$ & $30.403783^{\circ}$ & 16.64 & 2.40 \\
PCPT-04 & $40.734927^{\circ}$ & $30.410647^{\circ}$ & 15.60 & 3.30 & PCPT-17 & $40.733669^{\circ}$ & $30.403305^{\circ}$ & 17.64 & 2.50 \\
PCPT-05 & $40.733940^{\circ}$ & $30.410787^{\circ}$ & 14.44 & 3.50 & PCPT-9.1 & $40.733700^{\circ}$ & $30.409800^{\circ}$ & 17.24 & 2.00 \\
PCPT-06 & $40.735011^{\circ}$ & $30.409863^{\circ}$ & 16.62 & 2.00 & PCPT-9.2 & $40.733700^{\circ}$ & $30.410200^{\circ}$ & 15.14 & 2.20 \\
PCPT-07 & $40.734807^{\circ}$ & $30.409091^{\circ}$ & 14.40 & 2.10 & PCPT-9.3 & $40.734500^{\circ}$ & $30.410100^{\circ}$ & 14.94 & 2.60 \\
PCPT-08 & $40.733971^{\circ}$ & $30.409148^{\circ}$ & 15.64 & 2.10 & PCPT-9.4 & $40.734500^{\circ}$ & $30.409700^{\circ}$ & 16.66 & 1.50 \\
PCPT-09 & $40.734798^{\circ}$ & $30.408319^{\circ}$ & 17.66 & 1.70 & PCPT-21.1 & $40.733500^{\circ}$ & $30.405200^{\circ}$ & 10.46 & 1.50 \\
PCPT-10 & $40.734098^{\circ}$ & $30.408362^{\circ}$ & 15.10 & 2.60 & PCPT-21.2 & $40.734000^{\circ}$ & $30.405500^{\circ}$ & 17.62 & 1.60 \\
PCPT-11 & $40.734254^{\circ}$ & $30.407593^{\circ}$ & 15.08 & 1.90 & PCPT-21.3 & $40.733900^{\circ}$ & $30.404300^{\circ}$ & 15.64 & 1.90 \\
PCPT-12 & $40.734666^{\circ}$ & $30.407125^{\circ}$ & 15.14 & 1.70 & PCPT-21.4 & $40.733500^{\circ}$ & $30.404400^{\circ}$ & 12.70 & 1.70 \\
PCPT-13 & $40.734054^{\circ}$ & $30.406745^{\circ}$ & 16.64 & 2.30 & PCPT-21.5 & $40.733700^{\circ}$ & $30.404800^{\circ}$ & 13.62 & 1.70 \\
\hline
\end{tabular}

\section{Analizler}

$\mathrm{Bu}$ çalışma kapsamında; seçilen arazide gerçekleştirilen sondalama verilerinden elde edilen taşıma gücü değerleri ile sıvılaşma potansiyeli sonuçlarının haritalanması amaçlanmıştır. Tematik haritaların oluşturulması için MapInfo yazılımında belirli noktaların (örn. bu çalışma kapsamında CPT noktaları) öznitelik verilerini (örn. sondalamalardan hesaplanan taşıma gücü değerleri) kullanarak bilinmeyen alanların değerlerini tahmin etme amacı ile belirli enterpolasyon teknikleri kullanılmaktadır. Bunlardan bazıları; üçgen bölgeleme (triangulation with smoothing), uzaklığın tersi ile ağırlıklandırma (inverse distance weighting - IDW), doğal komşuluk (natural neighbor) ve iki aşamalı değer bulmadır (kriging).

\subsection{Taşıma gücü açısından dĕğerlendirme}

Birbirlerinden farklı alanlara sahip Küçük Sanayi Kooperatifi binalarının temelleri kısmen sürekli temel tipinde, kısmen de bodrumlu yayılı temel olarak düşünülmüştür. Şerit temellerin gömme derinliği $2.60 \mathrm{~m}$, temel genişliği ise $2.40 \mathrm{~m}$ olarak tasarlanmıştır. Temel taşıma gücü hesaplarında, temel tabanı altından temel genişliği kadar aşağısını kapsayacak bölgedeki zeminlerin drenajsız kayma direnci değerlerinin ortalamasının dikkate alınması yeterlidir. Araziyi kapsayan koni penetrasyon deneyi $(C P T)$ çalışmalarından elde edilen verilerden ortamın drenajsız kayma direncini $\left(c_{u}\right)$ Eşitlik 1 vasıtası ile elde etmek mümkündür.

$$
\mathrm{c}_{\mathrm{u}}=\left(\mathrm{q}_{\mathrm{c}}-\sigma_{\mathrm{o}}\right) / \mathrm{N}_{\mathrm{k}}
$$

Burada $N_{k}$ koni faktörüdür. Önalp ve diğ. (2006), Adapazarı zeminleri için $N_{k}$ değerini 14.55 olarak önermişlerdir [7]. Buna göre çalışma alanında hesaplanmış olan drenajsız kayma direnci 
değerleri Tablo 2'de verilmektedir. Üst kil tabakasının kalınlığı 5.00 metreyi geçmediği için ve yeraltı su seviyesinin de yüzeye en yakın yerde 1.70 metre olmasından dolayı bu aralıklardaki suya doygun kilin ortalama drenajsız kayma dirençleri temel genişliği göz önüne alınarak hesaplanmıştır. Çalışma alanı zeminlerinde temel taşıma gücü dağılımını yansıtabilmek amacıyla, yüzeye oturan bir şerit temelin drenajsız durum için taşıma gücü hesaplanarak haritalanmıştır. Bu geometride bir temelde, drenajsız koşullarda $\left(\phi_{u}=0\right)$ Skempton temel taşıma gücü formülünde taşıma gücü faktörü $N_{c}=6.3$ olmaktadır. Söz konusu alanda yapılması düşünülen yapılarda YASS'nin yüzeyde olduğu varsayımı ile minimum temel taşıma gücü;

$$
\sigma_{\mathrm{em}, \text { net }}=\left(\mathrm{c}_{\mathrm{u}} \mathrm{xN} \mathrm{N}_{\mathrm{c}}\right) / \mathrm{GS}
$$

formülü ile hesaplanabilir (GS: güvenlik sayısı). Bu yaklaşım ile hesaplanmış olan taşıma gücü değerleri ve buna bağlı olarak tahmin edilen yatak katsayıları $\left(k_{s}\right)$ [8] yine Tablo 2'de sunulmaktadir.

$$
\mathrm{k}_{\mathrm{s}}\left(\mathrm{kN} / \mathrm{m}^{3}\right)=\sigma_{\mathrm{em}}(\mathrm{kPa}) \mathrm{xGSx} 40
$$

Tablo 2. Drenajsız kayma direnci, taşıma gücü ve yatak katsayısı değerleri

\begin{tabular}{cccccc|cccccc}
\hline $\begin{array}{c}\text { PCPT } \\
\text { No }\end{array}$ & $\begin{array}{c}\text { Derinlik } \\
(\mathrm{m})\end{array}$ & $\begin{array}{c}\text { YASS } \\
(\mathrm{m})\end{array}$ & $\begin{array}{c}c_{u} \\
(\mathrm{kPa})\end{array}$ & $\begin{array}{c}\sigma_{\text {em,net }}(\mathrm{kPa}) \\
\left(\mathrm{kN} / \mathrm{m}^{3}\right)\end{array}$ & $\begin{array}{c}k \\
\text { No }\end{array}$ & $\begin{array}{c}\text { Derinlik } \\
(\mathrm{m})\end{array}$ & $\begin{array}{c}\text { YASS } \\
(\mathrm{m})\end{array}$ & $\begin{array}{c}c_{u} \\
(\mathrm{kPa})\end{array}$ & $\begin{array}{c}\sigma_{e m, n e t} \\
(\mathrm{kPa})\end{array}$ & $\begin{array}{c}k_{s} \\
\left(\mathrm{kN} / \mathrm{m}^{3}\right)\end{array}$ \\
\hline PCPT-01 & 13.64 & 3.10 & 79.12 & 166.15 & 19938 & PCPT-14 & 16.66 & 2.20 & 53.13 & 111.57 & 13388 \\
PCPT-02 & 17.68 & 2.30 & 71.82 & 150.82 & 18098 & PCPT-15 & 18.66 & 2.40 & 78.02 & 163.84 & 19661 \\
PCPT-03 & 9.42 & 2.00 & 81.44 & 171.02 & 20522 & PCPT-16 & 16.64 & 2.40 & 76.78 & 161.24 & 19348 \\
PCPT-04 & 15.60 & 3.30 & 56.44 & 118.52 & 14222 & PCPT-17 & 17.64 & 2.50 & 82.48 & 173.21 & 20784 \\
PCPT-05 & 14.44 & 3.50 & 66.14 & 138.89 & 16667 & PCPT-9.1 & 17.24 & 2.00 & 62.30 & 130.83 & 15699 \\
PCPT-06 & 16.62 & 2.00 & 76.40 & 160.44 & 19252 & PCPT-9.2 & 15.14 & 2.20 & 63.36 & 133.06 & 15966 \\
PCPT-07 & 14.40 & 2.10 & 70.75 & 148.58 & 17829 & PCPT-9.3 & 14.94 & 2.60 & 70.40 & 147.84 & 17740 \\
PCPT-08 & 15.64 & 2.10 & 65.57 & 137.70 & 16523 & PCPT-9.4 & 16.66 & 1.50 & 65.19 & 136.90 & 16427 \\
PCPT-09 & 17.66 & 1.70 & 64.70 & 135.87 & 16304 & PCPT-21.1 & 10.46 & 1.50 & 47.70 & 100.17 & 12020 \\
PCPT-10 & 15.10 & 2.60 & 74.56 & 156.58 & 18789 & PCPT-21.2 & 17.62 & 1.60 & 52.69 & 110.65 & 13277 \\
PCPT-11 & 15.08 & 1.90 & 71.84 & 150.86 & 18103 & PCPT-21.3 & 15.64 & 1.90 & 60.87 & 127.83 & 15339 \\
PCPT-12 & 15.14 & 1.70 & 63.33 & 132.99 & 15959 & PCPT-21.4 & 12.70 & 1.70 & 61.22 & 128.56 & 15427 \\
PCPT-13 & 16.64 & 2.30 & 68.82 & 144.52 & 17342 & PCPT-21.5 & 13.62 & 1.70 & 58.24 & 122.30 & 14676 \\
\hline
\end{tabular}

Bulunan bu değerler CBS ortamına aktarılarak tüm bloklar altında şerit temel için hesaplanmış taşıma gücü dağılımını gösteren tematik harita oluşturulmuştur (Şekil 3). Burada kırmızı alanlar $100-125 \mathrm{kPa}$, sarı alanlar $125-150 \mathrm{kPa}$ ve yeşil alanlar ise $150-175 \mathrm{kPa}$ aralığında taşıma güçlerine sahip bölgeleri göstermektedir. CBS kullanılarak oluşturulmuş görsel burada, böylesi bir alanda hangi bölgelerin diğerlerine nazaran farklı durumda olduğunu anlama açısından karar verme işlemini kolaylaştırmaktadır. Buna göre 8, 19 ve 21 nolu bloklar 100-125 kPa gibi en düşük taşıma gücüne sahip bölgeler ise de söz konusu bu değer aralığı, inşa edilmesi düşünülen yapıları, taban basınçlarının $80 \mathrm{kPa}$ civarında olmasından dolayı, taşıma gücü problemi yaşanmaksızın taşıyabilecek düzeydedir. Bunun yanı sıra alanın büyük bir çoğunluğunda şerit temel taşıma gücü $135 \mathrm{kPa}$ ’n üzerindedir. 


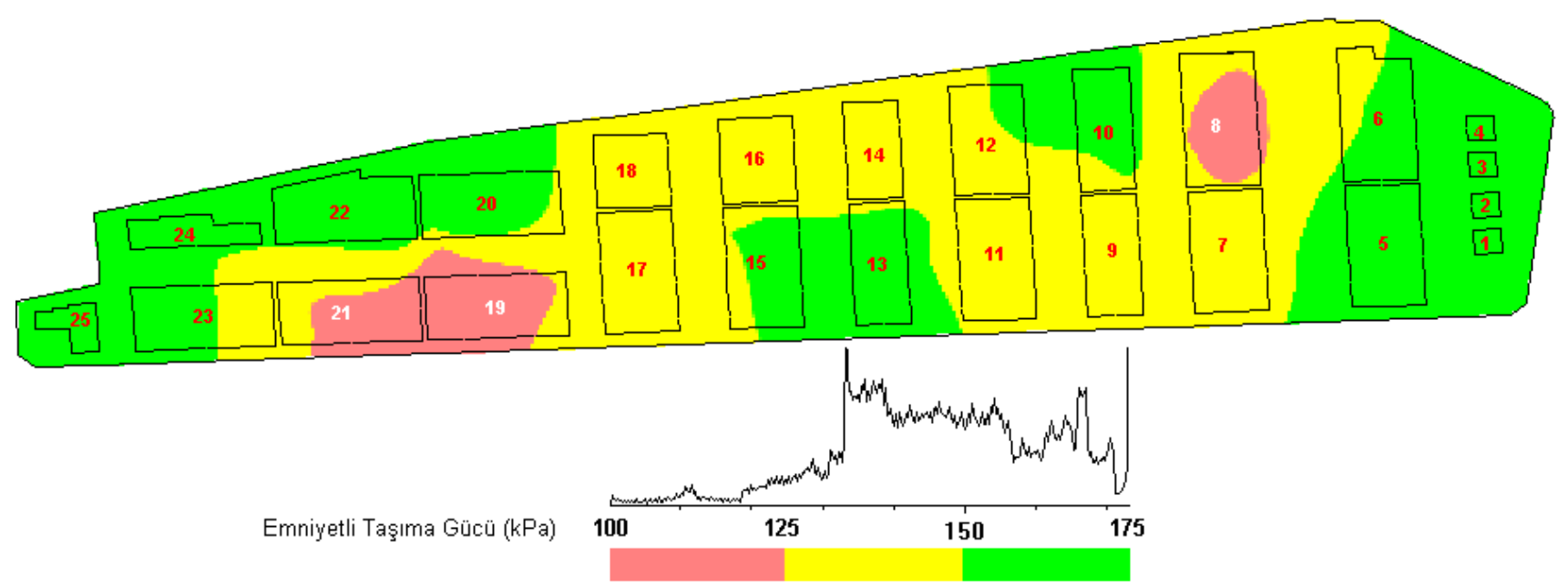

Şekil 3. Küçük Sanayi Sitesi Blokları Emniyetli Taşıma Gücü Dağılım Haritası

\subsection{Sıvılaşma potansiyeli açısından değerlendirme}

Öncelikle belirtilmelidir ki çalışma alanı yaklaşık 20-30 y1llık aralıklarla beliren $M=6.5-7.5^{\prime}$ lik deprem riskiyle karşı karşıyadır. İstatistiklere bakıldığında söz konusu depremin önümüzdeki yakın yıllarda olma olasılığı oldukça yüksektir. Bu nedenle yapı temellerinin $a_{h}=0.4 g$ gibi bir yatay ivme alacă̆ı hatırda tutulmalıdır. Yakın geçmişe kadar sıvılaşmaya yönelik zemin incelemeleri genellikle sondaj sırasında yapılan standart penetrasyon (SPT) deney sonuçlarına dayandırılmakta idi. Bugün de durumun fazlaca değiştiği söylenememektedir. Sondajlarda SPT deneyleri ile sağlanan darbe sayıları yanında, elde edilen örselenmiş numunelerden ortamın fiziksel, ayrıca alınacak örselenmemiş numunelerden de mekanik özellikleri tayin edilmeye çalışılmaktadır. Bununla birlikte, gelişen teknoloji ile boşluk suyu basınçlarının da ölçülebildiği koni penetrasyon deneyi ( $P C P T)$ birçok ülkede önemli bir uygulama alanı bulmuş ve geleneksel yöntem olarak kabul edilen standart penetrasyon deneyinin $(S P T)$ yerini almaya başlamış̧ır. $S P T$ veya $C P T$ deney sonuçları ile kumların sıvılaşma potansiyelinin değerlendirilmesi için çoğunlukla deprem sırasında zeminin direncini yansıtan çevrimsel kayma mukavemeti oranı $(C R R)$ ile depremden kaynaklanan çevrimsel kayma gerilmesi oranı $(C S R)$ karşılaştırılmaktadır $[9,10]$. Bu yöntemde; bir dizayn depremi tarafından oluşturulan çevrimsel kayma gerilmesi oranı "cyclic stres ratio" (CSR) ve zeminin direncini yansıtan çevrimsel kayma mukavemeti oranının "cyclic resistance ratio" $(C R R)$ tahmin edilmesi gerekmektedir. Eğer CSR, CRR'dan büyük ise çevrimsel sıvılaşma meydana gelebilir. CSR' 'n tahmini için basitleştirilmiş bir prosedür Seed ve Idriss (1971) tarafindan verilmiştir [9]:

$$
C S R=\frac{\tau_{a v}}{\sigma_{v o}^{\prime}}=0.65\left[\frac{a_{\max }}{g}\right]\left(\frac{\sigma_{v o}}{\sigma_{v o}^{\prime}}\right) r_{d}
$$

Burada, $\tau_{a v}$ ortalama çevrimsel kesme gerilmesi, $a_{\max }$ zemin yüzeyinde maksimum yatay ivme, $g=9.81 \mathrm{~m} / \mathrm{s}^{2}$ yerçekimi ivmesi, $\sigma_{v o}$ ve $\sigma_{v o}^{\prime}$ toplam ve efektif düşey örtü yükü basıncı ve $r_{d}$ derinliğe bağlı gerilme azaltma faktörüdür. $r_{d}$ 'nin tahmini için değişik araştırmacıların sunduğu bazı formülasyonlar bulunmaktadır. Seed ve Idriss (1971) aşağıdaki basit bağıntıları önermiştir [9]; 


$$
\begin{array}{ll}
\text { eğer } z<9.15 m & \Rightarrow r_{d}=1.0-0.00765 z \\
\text { ĕger } z=9.15-23 m & \Rightarrow r_{d}=1.174-0.0267 z
\end{array}
$$

Son yıllarda ise CPT kesintisiz okuma alması, güvenilirlik ve tekrar edilebilirliğinin yüksek olmasından dolayı CRR'ı tahmin etmede diğer arazi deneylerine göre daha popüler olmuştur. Robertson ve Wride (1998) CRR’’ belirlemek için aşağıdaki formülleri önermiştir [11].

$$
50<\left(\mathrm{q}_{\mathrm{c} 1 \mathrm{~N}}\right)_{\mathrm{cs}} \leq 160 \Rightarrow C R R_{7.5}=93\left[\frac{\left(q_{c 1 N}\right)_{c s}}{1000}\right]^{3}+0.08 \mathrm{ve}\left(\mathrm{q}_{\mathrm{clN}}\right)_{\mathrm{cs}}<50 \Rightarrow C R R_{7.5}=0.833\left[\frac{\left(q_{c 1 N}\right)_{c s}}{1000}\right]+0.05
$$

Burada $\left(q_{c 1 N}\right)_{c s}$ normalleştirilmiş eş temiz kum penetrasyon direncidir. Burada $\left(q_{c l N}\right)_{c s}$ için aşağıdaki formülü kullanılır:

$$
\left(q_{c 1 N}\right)_{c s}=K_{c}\left(q_{c 1 N}\right)
$$

$K_{c}$ zeminin dane karakteristiğini ifade eden bir düzeltme faktörüdür. $K_{c}$ 'nin tahmini için zemin davranış tipi indeksinin $\left(I_{c}\right)$ kullanılmasını önerilmiştir [11], burada $I_{c}$ :

$$
I c=\sqrt{[3.47-\log Q]^{2}+[1.22+\log F]^{2}}
$$

ile bulunur ve

$$
Q=q_{c 1 N}=\left(\frac{q_{c}-\sigma_{v o}}{P_{a 2}}\right)\left(\frac{P_{a}}{\sigma_{v o}^{\prime}}\right)^{n}
$$

normalleştirilmiş CPT penetrasyon direncidir ve boyutsuzdur. $n=$ gerilme üssü; $F=f_{s} /\left[\left(q_{c^{-}}\right.\right.$ $\left.\left.\sigma_{v o}\right)\right] \times 100$ yüzde cinsinden normalleştirilmiş sürtünme oranıdır. $f_{s}$ sürtünme direncidir; $\sigma_{v o}$ ve $\sigma_{v o}^{\prime}$ toplam ve efektif düşey örtü yükü basınc1; $P_{a}$ bir referans basınçtır ve $\sigma_{\text {vo }}^{\prime}$ ile aynı birimdedir (örn. eğer $\sigma_{v o}^{\prime} \mathrm{kPa}$ ise $P_{a}=100 \mathrm{kPa}$ 'dır). Diğer bir referans basınç olan $P_{a 2}, q_{c}$ ve $\sigma_{v o}$ ile aynı birimdedir (örn. eğer $q_{c}$ ve $\sigma_{v o} \mathrm{MPa}$ ise $P_{a 2}=0.1 \mathrm{MPa}$ dır). Robertson (2004) n değerinin ilk önce $n=1$ alınarak $Q$ ve $F^{\prime \prime}$ nin tayininden sonra bir $I_{c}$ değerinin elde edilmesini ve buna göre de aşağıdaki yöntemin kullanılabileceğini söylemiştir [12]:

$$
\begin{array}{ll}
\text { eğer } & I_{c}<1.64 \Rightarrow n=0.5 \\
\text { eğer } & I_{c}>3.30 \Rightarrow n=1.0 \\
\text { eğer } & 1.64<I_{c}<3.30 \Rightarrow n=\left(I_{c}-1.64\right) 0.3+0.5
\end{array}
$$

Burada gerilme sabitindeki değişim $\Delta n<0.01$ oluncaya kadar iterasyon yapılır. $I_{c}$ ile $K_{c}$ arasındaki ilişki şu formülle verilmiştir: 


$$
\begin{aligned}
& \mathrm{K}_{\mathrm{c}}=1.0 \text { eğer } I_{c} \leq 1.64 \\
& K_{c}=-0.403 I_{c}^{4}+5.581 I_{c}^{3}+33.75 I_{c}-17.88 \text { eğer } \mathrm{I}_{\mathrm{c}}>1.64
\end{aligned}
$$

Sonuçta sıvılaşmaya karşı direnç: $F S=\frac{C R R_{7.5}}{C S R} M S F$ formülü ile verilir. Burada $M S F=\frac{174}{M^{2.56}}$ deprem büyüklüğü ölçek faktörüdür ( $M=$ depremin büyüklü̆ğü).

Bunun yanında, Iwasaki vd. (1978)'nin geliştirdiği, sıvılaşma potansiyelinin tahmini için sıvılaşma potansiyel indisi $(L P I)$ yöntemi mevcuttur [13]. Bu yönteme göre, sıvılaşmanın büyüklüğü sıvılaşan tabaka kalınlığına, bunun yüzeye olan yakınlığına ve sıvılaşmaya direncin deprem tarafından beliren yüke oranını ifade eden güvenlik katsayısının birden küçük olduğu orana bağlıdır. Burada FS sıvılaşmaya karşı direncin deprem tarafından beliren yüke oranını göstermektedir. 20 m'den daha büyük derinliklerde oluşacak sıvılaşmanın etkisinin yüzeyde çok nadir belireceği gerekçesiyle araştırmacılar, LPI'nın hesabını 0 ile $20 \mathrm{~m}$ arasında sınırlandırmışlar ve aşağıda verilen tanımlamayı önermişlerdir.

$$
L P I=\int_{0}^{20 m} F w(z) d z
$$

Burada $z$ metre boyutunda derinlik, $w$ ise derinliğe bağlı ağırlık faktörü olmak üzere;

$$
\begin{aligned}
& F S \leq 1 \Rightarrow F=1-F S \\
& F S>1 \Rightarrow F=0 \text { ve } \\
& w(z)=10-0.5 z \text { dir. }
\end{aligned}
$$

Buradan, bulunan LPI değerinin Tablo 3'de verilen aralıklarına göre sıvılaşma potansiyelinin büyüklüğü tahmin edilebilmektedir. Toprak ve Holzer (2003) 1989 Loma Prieta, California depremindeki sıvılaşmanın yüzey gözlemleri ile LPI korelasyonunu incelemişler ve sıvılaşma olayının tipik olarak LPI'nin 5 değerini aştığı durumlarda gerçekleştiğini belirlemişlerdir [14].

Tablo 3. Sıvılaşma Potansiyel İndisine göre sıvılaşmanın şiddeti

\begin{tabular}{cc}
\hline Sıvılaşmanın şiddeti & $L P I$ \\
\hline Az-yok & $L P I=0$ \\
Küçük & $0<L P I<5$ \\
Orta & $5<L P I<15$ \\
Büyük & $15<L P I$ \\
\hline
\end{tabular}

Bu çalışma kapsamında tüm CPT'lerde sıvılaşma analizleri yukarıda anlatılan çevrimsel gerilme yöntemine göre yapılmış ve her sondalamada sıvılaşma potansiyeli indisi tayin edilmiştir. Örnek olarak; CPT-01 çalışma alanının en doğu kesiminde yapılmış olup tüm kesit boyunca $L P I=5.46$ düzeyindedir. Buna karşın çalışma alanının güney-batı kesimlerinde gerçekleştirilen CPT-21-5 nolu sondada $L P I=25.05$ olarak analiz edilmiş olup büyük oranda sıvılaşma potansiyelini işaret etmektedir. Tablo 4'te gerçekleştirilen sıvılaşma analizlerinin özet sonuçları görülmektedir. Çalışma alanının yol seviyesine göre alçak kotu nedeni ile arazide yer yer 2.00-2.50 metrelere 
varan dolgu yapılması öngörülmektedir. Bu sebeple efektif gerilmelerde artış meydana gelecek bu da sıvılaşma potansiyelini aşağı seviyelere çekecektir. Bu dolgunun bir diğer olumlu etkisi de sıvılaşabilir tabakaların yüzeye olan mesafesini arttıracaktır. Dolgunun bu olumlu etkisini göz önüne alabilmek için üst 10 metrenin sıvılaşma potansiyeli de hesaplanmış ve sonuçları yine Tablo 4'te sunulmuştur.

Tablo 4. Sıvılaşma analizleri özeti

\begin{tabular}{lcccccc}
\hline PCPT No & Derinlik $(\mathrm{m})$ & YASS $(\mathrm{m})$ & LPI tüm & LPI_10m & LQlayer_tüm & LQlayer_10m \\
\hline PCPT-01 & 13.64 & 3.1 & 5.46 & 2.99 & 1.74 & 0.90 \\
PCPT-02 & 17.68 & 2.3 & 5.94 & 3.95 & 1.72 & 0.98 \\
PCPT-03 & 9.42 & 2.0 & 3.96 & 3.96 & 1.12 & 1.12 \\
PCPT-04 & 15.6 & 3.3 & 6.16 & 5.14 & 1.88 & 1.50 \\
PCPT-05 & 14.44 & 3.5 & 5.36 & 4.82 & 1.52 & 1.32 \\
PCPT-06 & 16.62 & 2.0 & 8.79 & 8.05 & 2.32 & 2.06 \\
PCPT-07 & 14.4 & 2.1 & 7.49 & 6.70 & 1.92 & 1.68 \\
PCPT-08 & 15.64 & 2.1 & 9.71 & 9.15 & 2.48 & 2.26 \\
PCPT-09 & 17.66 & 1.7 & 9.96 & 9.59 & 2.54 & 2.40 \\
PCPT-10 & 15.1 & 2.6 & 12.89 & 11.28 & 3.32 & 2.74 \\
PCPT-11 & 15.08 & 1.9 & 10.86 & 10.1 & 2.46 & 2.18 \\
PCPT-12 & 15.14 & 1.7 & 11.78 & 10.48 & 3.02 & 2.54 \\
PCPT-13 & 16.64 & 2.3 & 5.70 & 3.01 & 1.78 & 0.86 \\
PCPT-14 & 16.66 & 2.2 & 10.61 & 7.65 & 2.94 & 1.98 \\
PCPT-15 & 18.66 & 2.4 & 16.08 & 13.89 & 4.22 & 3.52 \\
PCPT-16 & 16.64 & 2.4 & 16.05 & 13.87 & 4.04 & 3.32 \\
PCPT-17 & 17.64 & 2.5 & 14.06 & 12.84 & 3.54 & 3.14 \\
PCPT-9.1 & 17.24 & 2.0 & 12.26 & 9.25 & 3.06 & 2.00 \\
PCPT-9.2 & 15.14 & 2.2 & 10.79 & 9.34 & 2.66 & 2.12 \\
PCPT-9.3 & 14.94 & 2.6 & 8.29 & 6.44 & 2.54 & 1.84 \\
PCPT-9.4 & 16.66 & 1.5 & 12.31 & 11.13 & 3.12 & 2.66 \\
PCPT-21.1 & 10.46 & 1.5 & 3.05 & 2.28 & 1.16 & 0.70 \\
PCPT-21.2 & 17.62 & 1.6 & 9.22 & 6.43 & 2.46 & 1.48 \\
PCPT-21.3 & 15.64 & 1.9 & 19.00 & 16.87 & 4.96 & 3.96 \\
PCPT-21.4 & 12.70 & 1.7 & 19.46 & 16.24 & 4.76 & 3.62 \\
PCPT-21.5 & 13.62 & 1.7 & 25.05 & 21.18 & 5.62 & 4.32 \\
\hline
\end{tabular}

Tablo 4 sonuçları veri tabanına aktarılıp GBS ile ilişkilendirildiğinde istenilen sıvılaşma tematik haritasının hazırlanması mümkün olmaktadır. Tablo halinde verilen bu sonuçlar CBS ile değerlendirildiğinde daha büyük anlamlar taşımaktadır. Zira sıvılaşır ve sıvılaşmaz tabakaların bulunduğu bölgelerin dağılımı belli bir komşuluk ilişkisini ortaya koymaktadır. Böylelikle $C B S$ ortamında haritalama yapıldığında arazideki risk durumunu ifade eden LPI dağılımı kolaylıkla izlenebilmektedir (Şekil 4). Haritalar hem tüm derinlik boyunca ölçülen CPT verilerine göre hem de daha riskli olduğu için üst 10 metre verisi kullanılarak hazırlanmıştır. Bu haritalardan arazide bulunan 20-21-22-23 ve 24 nolu blokların yüksek oranda sıvılaşma riski taşıdığı anlaşılmaktadır. $\mathrm{Bu}$ da arazinin batı kesimlerinin sıvılaşma açısından doğu kesimlerine oranla daha riskli çıktığını göstermektedir. Arazinin batı kesimlerinde sıvılaşabilir tabaka kalınlıklarının 4.00-5.00 metre aralığına ulaştığı ve yüzeye daha yakın olduğu da anlaşılmıştır. Bu nedenle adı geçen bloklarda zemin iyileştirmesi yapılması gerekmektedir. 


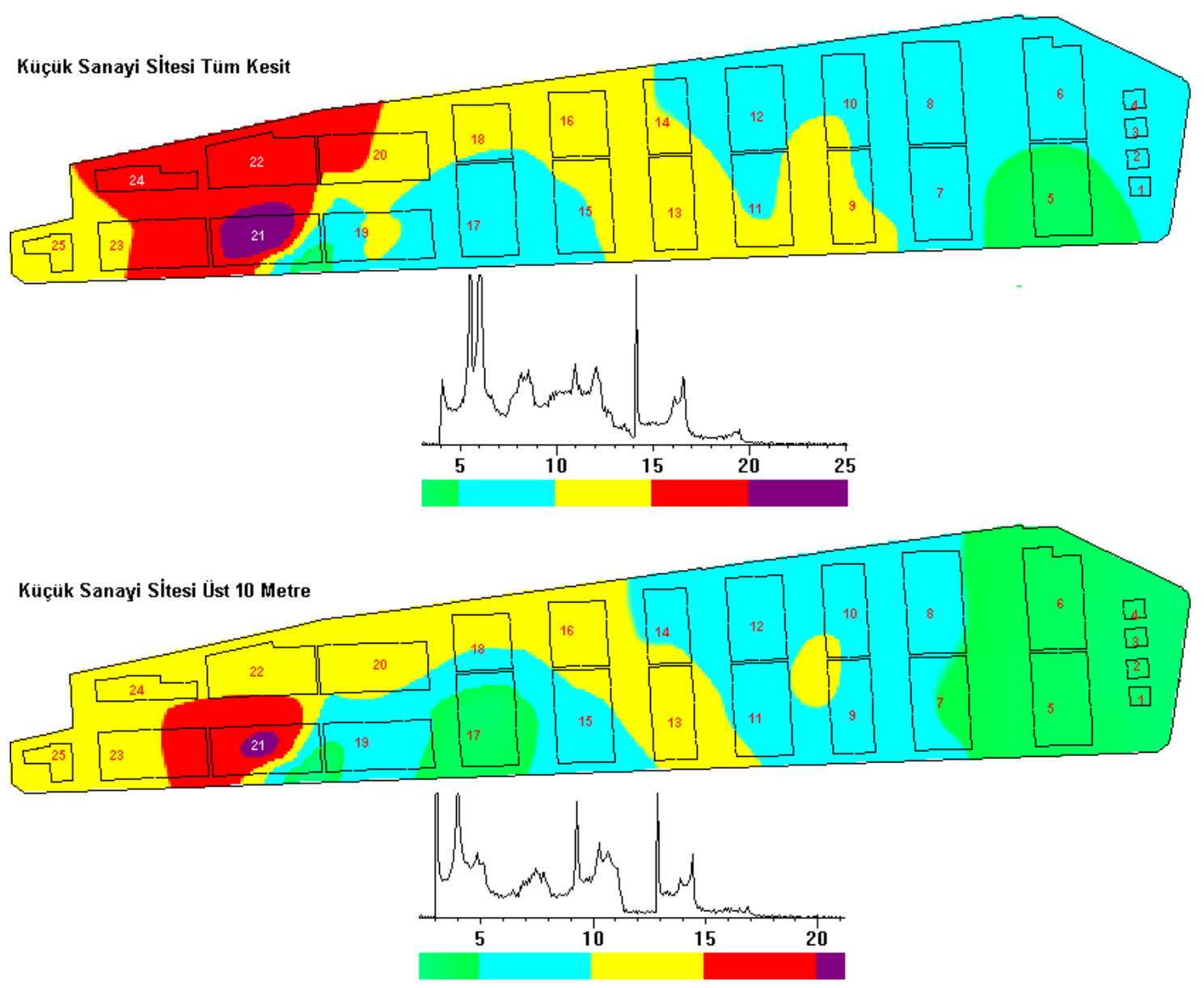

Şekil 4. Küçük Sanayi Sitesi Blokları Sıvılaşma Potansiyeli İndeksi (LPI) dağılım haritası

\section{Sonuç}

$\mathrm{Bu}$ çalışmada orta ölçekli bir araştırma alanında Geoteknik değerlendirmenin CBS eşliğinde yürütülmesi açıklanmıştır. Çalışma alanında koni penetrasyon deneyleri (PCPT) Sakarya Üniversitesi İnşaat Mühendisliği Geoteknik Laboratuvarı bünyesinde gerçekleştirilmiştir. Altlık olarak kullanılan blokların oturma planı, Coğrafi Bilgi Sistemi (CBS/GIS) yazılımı olan MapInfo programı ile sayısallaştırılmıştır. Map-Info haritaları ile veri tabanı arasında gerekli ilişkiler kurularak sonuca ulaştıracak taşıma gücü ve sıvılaşma bölgelerini gösterir tematik haritalar hazırlanmıştır. Söz konusu tematik haritalar yardımı ile gerekli yerlerde temel güçlendirmesi açısından önerilerde bulunulmuştur. Çalışma alanında daha önceden hazırlanmış klasik sondajlı zemin inceleme raporunda sonuç olarak tüm alanın iyileştirilmesi gerektiğinin belirtildiği hatırlanırsa Coğrafi Bilgi Sistemlerinin yanalda ve düşeyde ani zemin profili değişimi gösteren alüviyal kökenli çökel ortamlarda Geoteknik bakımdan karar verme süreçlerini hızlandırdığını ve yapılan değerlendirmelerin de daha doğruyu yansıttığını söylemek yanlış olmayacaktır. Bununla birlikte eğer inceleme noktalarının araziye düzgün dağılımını sağlayan uygun bir arazi programı gerçekleştirilirse CBS'nin çalışmalara hız katacağı ve maliyetleri düşüreceği görülecektir. 


\section{Kaynaklar}

[1] Fitzpatrick C and Maguire DJ. GIS in schools: Infrastructure, methodology and role in GIS. A sourcebook for schools (Ed: Green, D.R.), Taylor \& Francis (2000), p. 61-62.

[2] Bol E. Adapazarı zeminlerinin geoteknik özellikleri, Doktora Tezi, Sakarya Üniversitesi, Fen Bilimleri Enstitüsü (2003).

[3] Bol E. Determination of the relationship between soil properties and earthquake damage with the aid of neural networks: a case study in Adapazar1, Turkey. Natural Hazards and Earth System Sciences 2012; 12: 2965-2975, DOI: 0.5194/nhess-12-2965-2012.

[4] Bol E, Önalp A, Arel E, Sert S, Özocak A. Liquefaction of silts: the Adapazari criteria", Bulletin of Earthquake Eng. 2010; 8: 859-873, DOI: 10.1007/s10518-010-9174-x.

[5] Bray JD, Sancio RB, Durgunoglu T, Onalp A, Youd TL, Stewart JP, Seed RB, Çetin KÖ, Bol E, Baturay MB, Christensen C, Karadayilar T. Subsurface characterization at ground failure sites in Adapazar1, Turkey. Journal of Geotechnical and Geoenvironmental Engineering (ASCE) 2004; 130: 673685, DOI: 0.1061/(ASCE)1090-0241(2004)130:7(673).

[6] Önalp A, Arel E, Bol E. A general assesment of the effects of 1999 earthquake on the soil-structure interaction in Adapazarı, jubilee papers in honour of Prof. Dr. Ergün Toğrol (Editors: A. Sağlamer, K. Özüdoğru, S. Gök, A. Kurtuluş), Istanbul, Turkey, ITU Press (2001), p. 76-89.

[7] Önalp A, Bol E, Ural N. Estimation of undrained shear strength from cone tip resistance in clayey soils, Proceedings of Seventh International Congress on Advances in Civil Engineering, Y1ldiz Technical University, İstanbul, Turkey, 2006, p. 1-12.

[8] Bowles JE. Foundation Analysis and Design", $4^{\text {th }}$ Edition, McGraw Hill (1988).

[9] Seed HB and Idriss IM. Simplified procedure for evaluating soil liquefaction potential. J. of the Soil Mechanics and Foundations Division, ASCE 1971; 97: 9: 1249-1273.

[10] Youd TL, Idriss IM, et al. Liquefaction resistance of soils. Summary report from the NCEER and NSF workshops, Journal of Geotechnical Geoenvironmental Engineering 2001; 127: 10: 817-833.

[11] Robertson PK and Wride C. Evaluating cyclic liquefaction potential using the cone penetration test. Canadian Geotechnical Journal 1998; 35: 442-459. http://dx.doi.org/10.1139/t98-017

[12] Robertson PK. Evaluating soil liquefaction and post-earthquake deformations using the CPT, University of Alberta, Canada (2004), Available by Prof. P. Robertson's website (https://www.cptrobertson.com/publications/-date of access: 10.10.2018).

[13] Iwasaki T, Tokida K, Tatsuko $\mathrm{F}$ and Yasuda S. A practical method for assessing soil liquefaction potential based on case studies at various site in Japan, $2^{\text {nd }}$ International Conference on Microzonation, San Francisco 1978, p. 885-896.

[14] Toprak S and Holzer TL. Liquefaction potential index: field assessment, J. of Geotechnical and Geoenvironmental Engineering, ASCE 2003, 129: 4: 315-322. 